\title{
Exploring the bargaining space within international climate negotiations based on political, economic and environmental considerations
}

\author{
Angelica Mendoza Beltran ${ }^{\mathrm{a}, *}$, Michel G.J. den Elzen ${ }^{\mathrm{a}}$, Andries F. Hof ${ }^{\mathrm{a}}$, \\ Detlef P. van Vuuren ${ }^{\mathrm{a}, \mathrm{b}}$, Jasper van Vliet ${ }^{\mathrm{a}}$ \\ ${ }^{a}$ Netherlands Environmental Assessment Agency, Department of Climate, Air and Energy, P.O. Box 303, 3720 AH Bilthoven, The Netherlands \\ ${ }^{\mathrm{b}}$ Utrecht University, Utrecht Sustainability Institute, Heidelberglaan 2, 3584 CS Utrecht, The Netherlands
}

\section{A R T I C L E I N F O}

\section{Article history:}

Received 31 July 2010

Accepted 28 August 2011

Available online 16 September 2011

Keywords:

Abatement costs

Two degree target

Copenhagen accord

\begin{abstract}
A B S T R A C T
This study provides a conceptual framework for exploring the bargaining space within international climate negotiations based on important economic, political and environmental considerations. Based on it, we analyse combinations of the proposed emission reduction ranges for Annex I countries as a group (25-40\% below 1990 levels) and non-Annex I as a group (15-30\% below baseline) by 2020 to limit global warming to $2{ }^{\circ} \mathrm{C}$. We use results of the FAIR model with costs estimates based on two energy system models. We conclude that the range of targets that comply with a set of criteria for economic, political and environmental considerations is smaller than that by environmental considerations alone. More specifically, we find that according to our criteria, a 30\% Annex I reduction target below 1990 levels, combined with a 20\% non-Annex I reduction target below baseline emission levels (i.e. 20 to 30\% above 2005 levels), is the only combination of targets fulfilling all our criteria for both energy system models. Otherwise, reaching the $2{ }^{\circ} \mathrm{C}$ target becomes less likely, technically infeasible, or non-Annex I abatement costs are likely to exceed those of Annex I, a result, which we consider less plausible from a political viewpoint in our conceptual framework.
\end{abstract}

(c) 2011 Elsevier Ltd. All rights reserved.

\section{Introduction}

The ultimate goal of the United Nations Framework Convention on Climate Change (UNFCCC, 2011) is to stabilise atmospheric concentrations of greenhouse gases (GHG) at a level that prevents dangerous human interference with the climate system (UNFCCC, 1992). Late 2010, 140 countries have associated themselves with the Copenhagen Accord, which outlined the $2{ }^{\circ} \mathrm{C}$ target as an acceptable increase of global temperature:

"We agree that deep cuts in global emissions are required according to science, and as documented by the Intergovernmental Panel for Climate Change (IPCC) Fourth Assessment Report with a view to reduce global emissions so as to hold the increase in global temperature below 2 degrees Celsius...". More recently a similar formulation was included in the Cancun Agreements (2010). ${ }^{1}$

\footnotetext{
* Corresponding author. Tel.: +3130 2748691; fax: +31302744479.

E-mail address: angelica.mendozabeltran@pbl.nl (A. Mendoza Beltran).

${ }^{1}$ See The Cancun Agreements: Outcome of the work of the Ad Hoc Working Group on Long-term Cooperative Action under the Convention. Available at: http://unfccc.int/resource/docs/2010/cop16/eng/07a01.pdf\#page=2.
}

The relationship between temperature and GHG concentrations critically depends on climate system uncertainties. Achieving a $2{ }^{\circ} \mathrm{C}$ target with a probability above $50 \%$ would require stabilising GHG concentrations below approximately 450 parts per million (ppm) $\mathrm{CO}_{2}$ eq (Meinshausen et al., 2006). Scenarios leading to $450 \mathrm{ppm} \mathrm{CO}_{2}$ eq typically have a peak in global emissions in the coming two decades and show a reduction of emissions of $40-80 \%$ compared to the 2000 level by the middle of this century (see among others van Vuuren and Riahi, 2011, Metz et al., 2007; van Vuuren et al., 2007; Clarke et al., 2009; Edenhofer et al., 2010). The recent UNEP emissions gap report (UNEP, 2010) showed that scenarios with a likely chance (higher than 66\%) to meet a $2{ }^{\circ} \mathrm{C}$ target show a reduction of global emissions around 50-60\% compared to 1990 levels by the middle of this century.

Earlier, the IPCC Fourth Assessment Report (AR4) suggested that a $2{ }^{\circ} \mathrm{C}$ target would require Annex I (developed) countries as a group to reduce their emissions from $25 \%$ to $40 \%$ below 1990 levels by 2020 (Gupta et al., 2007). The Parties to the Ad Hoc Working Group on Further Commitments for Annex I Parties under the Kyoto Protocol (AWG-KP) agreed, in 2007, that this range would provide a practical basis for further consideration. den Elzen and Höhne (2008) elaborated further on the issue of required emission reductions by analysing a number of earlier studies about the emission reductions attributed to developed 
and developing countries for meeting long-term greenhouse gas concentration targets. They confirmed that a $25 \%$ to $40 \%$ reduction target in 2020 for Annex I countries as a whole would be consistent with a $450 \mathrm{ppm} \mathrm{CO}_{2} \mathrm{eq}$ target. Furthermore, an emission reduction target for non-Annex I countries of 15-30\% compared to baseline emission levels ${ }^{2}$ would be additionally required.

The analysis by den Elzen and Höhne (2008) is based on the assumption that there is a trade-off between emission reductions of Annex I and non-Annex I countries to reach a global target. Such a trade-off indeed exists from an environmental viewpoint, but economic and political considerations also need to be accounted for in international negotiations. Several studies have looked into economic and political considerations of allocating emissions, assuming that allocations that are perceived to be 'fair' have a higher feasibility (e.g., Metz et al., 2002). These studies looked at the expected costs or welfare effects of different emission allocation schemes (e.g., Knopf et al., 2010), or use more ad-hoc rules on emission allocation such as the EMF-22 study (see Clarke et al., 2009).

As part of the Copenhagen Accord, almost all Annex I countries have pledged quantified economy-wide emission targets for 2020 and about 45 non-Annex I countries have pledged mitigation actions. $^{3}$ Research has shown that the current pledges are not likely to be sufficient to reach the $2{ }^{\circ} \mathrm{C}$ target (e.g., UNEP, 2010; den Elzen et al., 2011a,b; Peterson et al., 2011). There will be an emissions gap between what is needed for meeting the $2{ }^{\circ} \mathrm{C}$ target and what is expected as a result of the pledges. According to UNEP (2010) this gap is about $5 \mathrm{GtCO}_{2} \mathrm{eq}$ for the most optimistic interpretation of the pledges. ${ }^{4}$ This gap could be closed if countries were to adopt more ambitious actions or pledges, as we will explore in this study based on an integrated model calculations with ambitious Annex I and non-Annex I reduction cases.

In the current climate negotiations towards the 17th Conference of Parties (COP17) to be held at Durban, South Africa, the possibility of more ambitious pledges and actions are still being discussed in both Ad-hoc working groups AWG-KP (Kyoto Protocol) and AWG-LCA (Long Term Cooperative Action under the UNFCCC) (see further discussion in Section 6).

The aim of this paper is to explore the space within international climate negotiations in terms of Annex I and non-Annex I reduction targets. We focus hereby on the above-mentioned ranges of $25-40 \%$ for Annex I and $15 \%-30 \%$ for non-Annex I in 2020. In order to explore the space, we develop a conceptual framework that takes into account important environmental, economic and political considerations. Such a framework may provide insight in some of the environmental, economic and political trade-offs, all of which are considered to be relevant for a successful outcome of the negotiations.

The paper is structured as follows. Section 2 describes the conceptual framework to explore the bargaining space. Section 3 presents the modelling framework, the baseline emission scenario, the mitigation cases and the main modelling assumptions. Section 4 presents the results and relates these to the conceptual framework. Section 5 describes the uncertainty introduced by the

\footnotetext{
${ }^{2}$ Baseline emission levels mean emission levels without specific climate policies, but including autonomous improvements in the energy efficiency and carbon intensity.

${ }^{3}$ See: http://unfccc.int/home/items/5264.php (Annex I countries) and http:// unfccc.int/home/items/5265.php (non-Annex I countries).

${ }^{4}$ The most optimistic interpretation of the pledges implies that countries implement their high ambitious, conditional pledges, subject to strict accounting of land use, land-use change and forestry activities and the use of surplus emission units.
}

level of emissions trading and finally, Section 6 discusses the results in terms of the current international climate negotiations developments and Section 7 concludes.

\section{Conceptual framework}

The bargaining space for setting 2020 emission targets in international negotiations on climate policy depends on several factors. Here, we explore this space by taking into account a set of criteria that includes environmental, economic and political considerations. We do so for two aggregate regions: Annex I (excluding Turkey and Kazakhstan) and non-Annex I.

From the environmental perspective, the most often used criterion is that global mean temperature increase needs to be limited to a maximum of $2{ }^{\circ} \mathrm{C}$. For this paper, we assume that the global emission level should remain below a threshold value in 2020 in order to stay on an emission pathway that could lead to a $2{ }^{\circ} \mathrm{C}$ target with a probability of more than $66 \%$.

The economic criterion we use is that global abatement costs ${ }^{5}$ should be as low as possible. This criterion has been important in international negotiations: it is the main reason why flexibilities such as emissions trading and the possibility of substitution across different gases are included in climate policy. As global costs are a major determinant for the regional costs, it is in the interest of all parties together to keep global costs to a minimum.

As for political considerations, we focus on two distributional criteria. The first is that non-Annex I abatement costs as share of GDP cannot be higher than those of Annex I (as a group). It is important to note here that we exclude possible side-payments for financing of mitigation actions in developing countries. The second criterion is that both Annex I and non-Annex I abatements costs as a group cannot be negative. The reason behind these distributional criteria relates to Article 3.1 of the UNFCCC (1992), which mentions that parties have "common but differentiated responsibilities and respective capabilities". It further specifically mentions "the developed country Parties should take the lead in combating climate change and the adverse effects thereof". Here, we interpret this as the widely accepted condition that Annex I costs as percentage of their income should not be smaller than non-Annex I costs, given both the capability of reducing emissions and the historical responsibility. For the second criterion, we assume that reduction targets that lead to negative costs for either Annex I or non-Annex I as a whole also has little political acceptance. Negative non-Annex I costs seems to be inconsistent with the notion of common responsibilities, not to mention negative Annex I costs. While in the past some scientific scholars have indicated that negative costs for non-Annex I parties might be an attractive way to combine climate policy and development assistance, in reality, there seems to be very little support for this in the negotiations. Moreover, direct financing of mitigation and adaptation actions in developing countries is an alternative or complementary instrument to emission reduction targets being explored under the current climate negotiations.

Fig. 1 shows the negotiation space based on these environmental, economic and political criteria in a schematic way. It relates Annex I and non-Annex I abatement costs based on different reduction targets for these regions. In this figure the upper right corner assumes stringent targets in both Annex I and non-Annex I regions, and thus a likely chance of meeting a $2{ }^{\circ} \mathrm{C}$ target-and correspondingly higher abatement costs (green area in Fig. 1). The bottom-left part of the figure represents very little

\footnotetext{
${ }^{5}$ Costs of emission reductions of all Kyoto greenhouse gases from all sources except from deforestation and bunkers, see Section 3.4 for further explanation.
} 


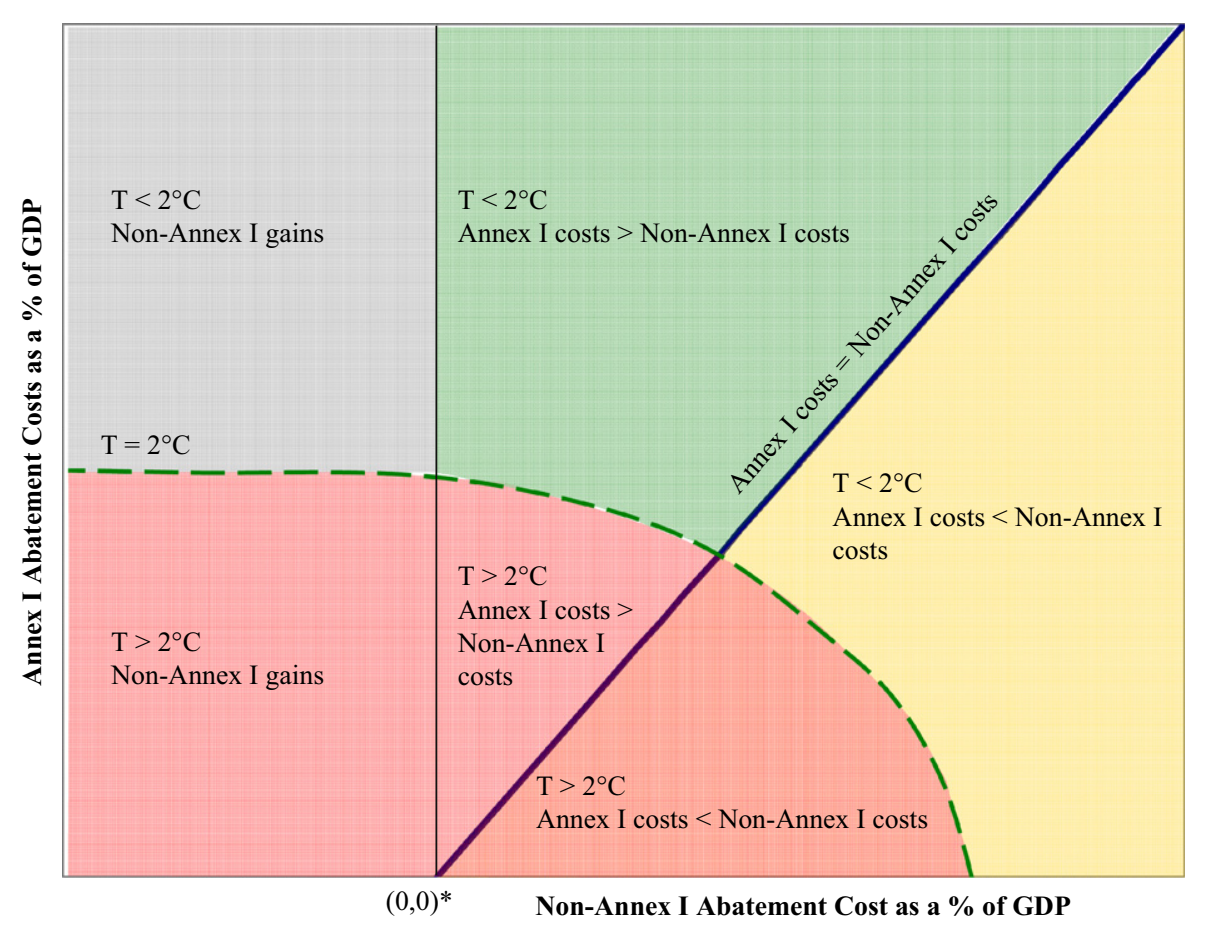

* In this point Annex I and non-Annex I have no abatement costs.

Fig. 1. Conceptual framework for the analysis. (For interpretation of the references to colour in this figure, the reader is referred to the web version of this article.)

reductions with low abatement costs and a small chance of meeting a $2{ }^{\circ} \mathrm{C}$ target. Somewhere between these two areas the probability of achieving a $2{ }^{\circ} \mathrm{C}$ target crosses the likely-unlikely threshold of $66 \%$ (dependent on the climate sensitivity and the shape of emission pathways). This is represented in Fig. 1 with a green dashed line. The area where the $2{ }^{\circ} \mathrm{C}$ target is unlikely is indicated in red.

The first political criterion of higher or equal costs for Annex I than for non-Annex I is indicated by the diagonal line. All costs combinations below this line imply higher non-Annex I than Annex I abatement costs (the yellow area). The vertical line represents the second political criterion; the grey area represents non-negative abatement costs for non-Annex I as a group. Combinations of reduction targets that end up in the green area fulfil all our criteria and combinations with lower global costs in this area are to be preferred according to our economic criterion. The conceptual framework as depicted in Fig. 1 can be used to address some important environmental, economic and political trade-offs of different combinations of Annex I and non-Annex I reduction targets for 2020 as we will show further in the analysis.

\section{Methodology and assumptions}

\subsection{Modelling framework}

The quantitative analysis of abatement costs in this paper is based on the integrated modelling framework FAIR ${ }^{6}$ (den Elzen et al., 2011a). FAIR integrates baseline emissions and information on marginal abatement costs by sectors (MAC curves). Based on

\footnotetext{
${ }^{6}$ The model names in this section are acronyms. FAIR=Framework to Assess International Regimes for the differentiation of commitments; IMAGE=Integrated Model to Assess the Global Environment and TIMER=The IMage Energy Regional model.
}

this, it calculates regional and global abatement costs given regional GHG emission targets. FAIR uses a cost-optimal implementation of these targets among regions, gases and sources through global trading of carbon credits. This means that the lowest cost mitigation options and technologies are used first.

The IMAGE land use model (Bouwman et al., 2006) provides the land use related baseline of GHG emissions used in FAIR. The TIMER energy model (van Vuuren et al., 2004, 2007) provides energy and industry related baseline emissions, as well as $\mathrm{CO}_{2}$ MAC curves. Section 3.2 presents the GHG emissions baseline scenario used for the calculations. The MAC curves of the energy and industry-related $\mathrm{CO}_{2}$ emissions are calculated in TIMER by imposing a carbon tax and recording the induced reduction of $\mathrm{CO}_{2}$ emissions. The MAC curves of the non- $\mathrm{CO}_{2}$ GHG emissions are exogenous to FAIR and based on Lucas et al. (2007). Using demand and supply curves, FAIR determines the carbon price in the international trading market, its buyers and sellers, and the resulting domestic and external abatement levels for each region.

Abatement costs (in 2005 USD) consist of domestic abatement costs, costs or revenues due to International Emission Trading (IET) and the use of offsets (Clean Development Mechanisms (CDM) or Joint implementation) at the level of 26 regions, shown in Table 1 . The abatement costs represent the direct additional costs due to climate policy. These present a first-order estimate of climate costs, but do not capture indirect macroeconomic implications. There are several reasons why macroeconomic costs may differ from abatement costs. Mitigation policies could, for instance, induce a reduced demand for fossil fuels, which could lead to additional income losses via fuel trade for fossil fuel exporters (OPEC countries, but also Russia and Canada; e.g., Dellink et al., 2010). Another example is that international trade in emission carbon credits will affect terms of trade (by changes in exchange rates). This will negatively affect carbon credit sellers (again, Russia is among them). Costs are also dependent on contextual factors such as energy prices and taxes (Klepper and 
Table 1

FAIR regional description.

\begin{tabular}{|c|c|}
\hline GROUP REGIONS & FAIR REGION CONFIGURATION \\
\hline Annex I & $\begin{array}{l}\text { Canada, USA, EU (Central and Western Europe), Russian Federation, Japan, Oceania (Australia and New Zealand) and Ukraine region } \\
\text { (Ukraine and Belarus): }\end{array}$ \\
\hline \multicolumn{2}{|r|}{ (2) } \\
\hline $\begin{array}{l}\text { Advanced developing } \\
\text { countries }\end{array}$ & $\begin{array}{l}\text { Mexico, rest of Central America, Brazil, rest of South America, South Africa, Kazakhstan region, Turkey, Middle East, Korea region and } \\
\text { China }\end{array}$ \\
\hline Other developing countries & Northern Africa region, India, rest of Southern Asia, Indonesia region, rest of South-East Asia \\
\hline Least developed countries & Western Africa, Eastern Africa and rest of South-Africa region \\
\hline
\end{tabular}

Peterson, 2006). It should be noted, however, that macroeconomic impacts are more uncertain. A comparison of costs estimates based on abatement costs and macroeconomic calculations showed nevertheless a high degree of correlation, so that abatement costs can be seen as a good proxy, in particular at the level of aggregated regions, as we present here (see van Vuuren et al., 2009). Furthermore, the MAC curves used here have been derived from energy models that account for dynamic effects (such as changing energy prices).

To explore the consequences of the uncertainty in cost estimates, we do not only use the TIMER based MAC curves and baseline emission information, but also the same information from the POLES model ${ }^{7}$ (Criqui et al., 1999; Russ and Criqui, 2007; Russ and Van Ierland, 2009). The POLES version of Enerdata (2010) is used. We only focus on the impact of using the energy-related $\mathrm{CO}_{2}$ MAC curves. Both sets of MAC curves (TIMER and POLES) are used in combination with their associated baseline scenario (see Section 3.2). POLES was selected to supplement the TIMER abatement costs since: (i) both models include a baseline accounting for the impact of the recent economic crisis; (ii) both models have information at the level of multiple sectors and world regions (both Annex I and non-Annex I), so it can be incorporated in our integrated model; (iii) both models show a wide range of outcomes across various models for Annex I as a group (e.g., Fig. 3.1 in Amann et al., 2009). Further information about both the TIMER and POLES model is provided in Appendix A.

\subsection{Baseline emission scenario}

The baseline emission scenario used as input for the FAIR model (i.e. in the absence of climate policy) was calculated using the IMAGE and TIMER models for the land use and energyindustry related emissions, respectively. These models are part of the Integrated Assessment Framework IMAGE 2.4. The scenario used here is based on an implementation of the IPCC SRES medium growth B2 scenario consistent with the IEA World Energy Outlook (IEA, 2007), and updated to take account for the economic crisis of 2008/2009 on the basis of IMF (2009) economic data. The main features (i.e. population, GDP per capita and emissions) of the baseline are presented in Table 2. From now on we refer this scenario as the IMAGE/TIMER scenario.

The scenario shows that energy demand continues growing mostly in developing countries, driven by high income growth while in developed countries it stabilizes. Also the scenario shows an increase in the production of agricultural products mostly driven by an increase in global population, a small increase in per capita consumption levels and a shift towards more meat intensive diets (van Vuuren et al., in press).

\footnotetext{
${ }^{7}$ The POLES model is a world simulation model for the energy sector. It works in a year-by-year recursive simulation and partial equilibrium framework, with endogenous international energy prices and lagged adjustments of supply and demand by world region.
}

Table 2

IMAGE/TIMER baseline for population, GDP per capita and anthropogenic Kyoto GHG emissions for the world and Annex I and non-Annex I regions over time.

\begin{tabular}{|c|c|c|c|c|c|c|c|c|c|}
\hline \multirow[t]{2}{*}{$\begin{array}{l}\text { IMAGE/TIMER } \\
\text { baseline }\end{array}$} & \multicolumn{3}{|c|}{$\begin{array}{l}\text { Population (in } \\
\text { million } \\
\text { inhabitants) }\end{array}$} & \multicolumn{3}{|c|}{$\begin{array}{l}\text { GDP }^{\mathrm{a}} \text { (USD } 1000 \\
\text { per capita) }\end{array}$} & \multicolumn{3}{|c|}{$\begin{array}{l}\text { GHG emissions, } \\
\text { excl. LULUCF and } \\
\text { bunkers } \\
\left(\mathrm{GtCO}_{2} \mathrm{eq}\right)\end{array}$} \\
\hline & 1990 & 2005 & 2020 & 1990 & 2005 & 2020 & 1990 & 2005 & 2020 \\
\hline Annex I & 1167 & 1224 & 1254 & 17.4 & 22.4 & 28.2 & 18.9 & 18.3 & 18.7 \\
\hline Non-Annex I & 4135 & 5287 & 6356 & 2.5 & 4.1 & 6.4 & 13.3 & 21.1 & 32.0 \\
\hline World & 5302 & 6512 & 7611 & 5.6 & 6.8 & 8.8 & 32.2 & 39.4 & 50.6 \\
\hline
\end{tabular}

${ }^{a}$ Annex I and non-Annex I GDP levels using Purchasing Power Parity (PPP) rates. World's GDP levels using Market Exchange Rates (MER).

The alternative dataset for POLES is based on the POLES reference scenario (i.e. in the absence of climate policy). The POLES baseline is broadly similar to the reference scenario of the IEA World Energy Outlook (IEA, 2009), and has been corrected for the economic crisis in a similar way as the IMAGE/TIMER scenario.

For the $\mathrm{CO}_{2}$ baseline emissions from land use, land use changes and forestry (i.e. deforestation) the scenario design for the OSIRIS project (Busch et al., 2009), using the Global Forestry Model from IIASA (Kindermann et al., 2008) is used. The global deforestation baseline emissions are around $4.3 \mathrm{GtCO}_{2}$ in 2020 according to the scenario used here.

Finally, the emissions resulting from international shipping transport (bunkers) amount to around $0.5 \mathrm{GtCO}_{2} \mathrm{eq}$ in the IMAGE/ TIMER baseline. International aviation is part of the transport sector and added to the total regional GHG emissions and therefore not reported separately or as part of the bunkers category. The emissions resulting from international aviation and shipping transport (bunkers) amount to $1 \mathrm{GtCO}_{2} \mathrm{eq}$ in the POLES baseline.

\subsection{Overview of analysed cases}

We analyse nine cases, each with a different combination of an Annex I and a non-Annex I reduction target. The cases have an Annex I reduction target between $25 \%$ and $40 \%$ below 1990 levels and a non-Annex I target between $15 \%$ and 30\% below baseline levels. $^{8}$ These ranges are in line with the reduction targets reported in IPCC AR4 Report (Annex I) and in den Elzen and Höhne (2008). Many countries have accepted these numbers as input for the climate negotiations during the Copenhagen and Cancun meetings (see, for example, European Council, 2011). Fig. 2 shows the reduction targets for the nine cases. The default calculations based on the IMAGE/TIMER baseline and abatement

\footnotetext{
${ }^{8}$ The reduction target range for non-Annex I below baseline levels (from 15 to $30 \%$ ) corresponds to an increase of emissions compared to 2005 levels between $5 \%$ and $30 \%$ for the TIMER cases and $15 \%$ and $40 \%$ for the POLES cases.
} 


\begin{tabular}{|c|c|c|c|c|c|c|c|c|c|}
\hline \multirow{2}{*}{\multicolumn{2}{|c|}{$\begin{array}{l}\text { TIMER MAC curves } \\
\text { cases }\end{array}$}} & \multicolumn{3}{|c|}{$\begin{array}{l}\text { Non-Annex I \% } \\
\text { compared to } \\
\text { Baseline Levels }\end{array}$} & \multirow{2}{*}{\multicolumn{2}{|c|}{$\begin{array}{l}\text { POLES MAC curves } \\
\text { cases }\end{array}$}} & \multicolumn{3}{|c|}{$\begin{array}{l}\text { Non-Annex I \% } \\
\text { compared to } \\
\text { Baseline Levels }\end{array}$} \\
\hline & & -15 & -20 & -30 & & & -15 & -20 & -30 \\
\hline \multirow{3}{*}{ 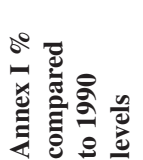 } & -25 & 1 & 2 & 3 & \multirow{3}{*}{ 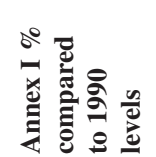 } & -25 & $1 p$ & $2 p$ & $3 p$ \\
\hline & -30 & 4 & 5 & 6 & & -30 & $4 p$ & $5 p$ & $6 p$ \\
\hline & -40 & 7 & 8 & 9 & & -40 & $7 p$ & $8 p$ & $9 p$ \\
\hline
\end{tabular}

Fig. 2. Annex I and non-Annex I aggregate regional reductions of the different cases.

costs have been named cases 1-9. These are referred to as the TIMER cases or TIMER MAC curves cases, as TIMER provides the energy-industry MAC curves. The corresponding cases based on the energy-related $\mathrm{CO}_{2}$ MAC curves and baseline of POLES, are labelled $1 \mathrm{p}-9 \mathrm{p}$ and are referred to as the POLES or POLES MAC curves cases.

For the regional allocation of the emission reductions within Annex I and non-Annex I, it is assumed that emissions are reduced by the same percentage below baseline emissions in every region. This allocation leads to the aggregate group targets presented in Fig. 2 below baseline for non-Annex I and below 1990 levels for Annex I. This type of allocation of emission targets is somewhat arbitrary, but as we focus on the results for the aggregated Annex I and non-Annex I regions here this assumption is sufficient. It should be noted that the results are not very sensitive to the allocation of emission reductions, since emissions trading is assumed (although not to their full potential in nonAnnex I regions, as will be explained in Section 3.4).

\subsection{Further modelling assumptions}

To assess the impact of Annex I and non-Annex I emission reduction targets on global emission reductions and abatement costs, the following general assumptions are made:

(i) The abatement costs calculations presented in this study include the costs of emission reductions of all Kyoto greenhouse gases from all sources, except from deforestation and bunkers, for which other assumptions on mitigation are made;

(ii) Global deforestation emissions in 2020 are assumed to be reduced by $30 \%$ below baseline based on a conservative estimate of the submitted mitigation actions from Brazil and Indonesia, as part of the Copenhagen Accord (den Elzen et al., 2011a). These leads to deforestation emissions of about $3 \mathrm{GtCO}_{2}$ in 2020;

(iii) For the emission reductions from Deforestation and Forest Degradation (REDD) we assume that CDM is not expanded with the REDD sector by $2020,{ }^{9}$ so REDD is not included in the carbon market and hence has no effect on the total abatement costs and global carbon price;

(iv) It is unclear, who will bear the costs from REDD. A possibility is that finance will come from independent bodies/funds (e.g., Amazon fund, Global Carbon Forestry

\footnotetext{
${ }^{9}$ The inclusion of the complex and controversial REDD sector in the carbon market via CDM is discussed in the literature (e.g., Eliasch, 2008; Karousakis and Corfee-Morlot, 2007). Given the uncertainties around REDD regarding monitoring, reporting and verifying performance, we have assumed that REDD is not included through a market-based mechanism. For analyses on REDD as a potential carbon market option see e.g., Fankhauser and Martin, 2010, Anger and Sathaye, 2008 and Bosetti et al., 2011. Moreover, the phased approach to implement REDD agreed in Cancun, suggests that market-based finance will only be achieved in the long term. Fund based finance is the alternative for the short term.
}

Partnership, UN-REDD programme, among others). This means it is very uncertain how the regional distribution of REDD costs will be. Therefore, we do not take them into account in the abatement costs projections of Annex I and non-Annex I. Since the costs of REDD are assumed not to depend on the global mitigation target, they have the same absolute effect on all our cases. The costs of REDD will therefore not change the relative ranking of the cases and we can thus exclude them from the global costs projections.

(v) International bunker emissions are assumed to follow their baseline developments, so no mitigation is assumed for this sector and therefore there are no mitigation costs. The reason for this assumption is that it is still unclear where negotiations on these emissions are leading and it is difficult to assign these emissions to specific regions;

(vi) Because we assume reduction targets below baseline for all countries, no banking of surplus 'assigned amount units' from the first commitment period is allowed ${ }^{10}$;

(vii) Transaction costs associated with the use of the Kyoto mechanisms are assumed to consist of a constant USD 0.5 per tonne $\mathrm{CO}_{2} \mathrm{eq}$ emissions plus $2 \%$ of the total costs (Michaelowa and Jotzo, 2005);

(viii) Credits resulting from land use and forestry rules in Annex I regions would result in additional emission allowances. Following den Elzen et al. (2011a) we have assumed that these additional allowances are about $2.5 \%$ of 1990 Annex I emissions (about $460 \mathrm{MtCO}_{2}$ ). This is based on the net-net accounting methodology, using the work of the Joint Research Centre (JRC);

(ix) In the calculations, non-Annex I countries finance their own reduction commitments, so we assume no international finance of mitigation actions (other than emission trading and CDM).

For the Kyoto period, it is assumed that all Annex I regions achieve the minimum of the Kyoto target or the baseline emissions in 2010, except for Canada and the United States of America (USA). For Canada it is already clear that the Kyoto target will not be reached and the USA did not ratify the Kyoto Protocol. Therefore, we assume baseline emission levels for these countries by 2010. For Russia and Ukraine, this implies that baseline emissions are used for 2010, because these are lower than their Kyoto target.

Regarding emissions trading between Annex I and non-Annex I, it is assumed that all Annex I regions fully participate in emissions trading by 2020. In the non-Annex I countries, CDM is possible, but not with their full potential for GHG mitigation given a certain carbon price due to the project basis of the CDM and implementation barriers such as properly functioning institutions and project size. Consistent with earlier studies

\footnotetext{
${ }^{10}$ In the first commitment period allowing banking and the use of the Kyoto surpluses implies that the assumed reduction targets for the Annex I countries in the calculations would need to be increased, to compensate these additional emissions.
} 
(Criqui, 2002; Jotzo and Michaelowa, 2002), this so-called CDM accessibility was set at $10 \%$ for least developed countries, $30 \%$ for other developing countries and $45 \%$ for advanced developing countries (see Table 1). This means that only between $10 \%$ and $45 \%$ of the total supply of carbon credits by non-Annex I regions for each carbon price, is available for offsetting reductions not achieved in Annex I countries.

We also analysed a more restricted CDM case to gain insight in the sensitivity of emissions trading on the results. In this case, the CDM accessibility is half of that used in the default scenarios as (see Section 5).

Finally, given the large differences in income between the regions, the regional costs (or gains) are presented as percentages of regional GDP levels using Purchasing Power Parity (PPP) rates. These are considered a better indicator of costs differences across regions than GDP values using Market Exchange Rates (MER), which are used for global costs.

\section{Environmental, political and economic criteria analysis}

\subsection{Environmental effectiveness: likelihood of meeting $2{ }^{\circ} \mathrm{C}$}

In order to assess the impact of the different cases on the likelihood of achieving a $2{ }^{\circ} \mathrm{C}$ target, the global emission level in 2020 resulting from the nine different cases are compared with the emission level required to reach a $450 \mathrm{ppm} \mathrm{CO}_{2}$ eq target. UNEP (2010) compiled the results of a number of studies to identify an emission level in 2020 consistent with the ambition to remain below the $2{ }^{\circ} \mathrm{C}$ target. This study concluded that emission pathways consistent with a probability higher than $66 \%$ of reaching the $2{ }^{\circ} \mathrm{C}$ target have an emission level in 2020 of 39 to 44 $\mathrm{GtCO}_{2} \mathrm{eq},{ }^{11}$ with a median estimate of $44 \mathrm{GtCO}_{2} \mathrm{eq}$ (also referred to as UNEP "likely chance" range for $2{ }^{\circ} \mathrm{C}$ target). The UNEP (2010) also mentions a range of 2020 emission levels consistent with a $50-66 \%$ probability to achieve a $2{ }^{\circ} \mathrm{C}$ target of 42 to $46 \mathrm{GtCO}_{2} \mathrm{eq},{ }^{12}$ with a median of $45 \mathrm{GtCO}_{2} \mathrm{eq}$ (also referred to as UNEP "medium chance" range for $2{ }^{\circ} \mathrm{C}$ target).

It should be noted, however, that the UNEP numbers are based on model simulations that looked into optimal pathways towards $2{ }^{\circ} \mathrm{C}$. It is possible that an emission level above $46 \mathrm{GtCO}_{2}$ eq could also still limit temperature change to $2{ }^{\circ} \mathrm{C}$ if followed by more rapid reductions later in the century (e.g., O’Neill et al., 2009).

Fig. 3 shows global projected emissions resulting from the Annex I and non-Annex I emissions targets for the different cases in 2020. It shows that most cases result in a 2020 emission level below $44 \mathrm{GtCO}_{2}$ eq. The only cases that result in an emission level above $44 \mathrm{GtCO}_{2} \mathrm{eq}$ are cases 1 and 4 as well as $1 \mathrm{p}$ and $4 \mathrm{p}$, which correspond to a $15 \%$ reduction below baseline levels for non-Annex I and a 25\% and 30\% reduction for Annex I, respectively. Global emissions in case $2 \mathrm{p}$ are also above $44 \mathrm{GtCO}_{2}$ eq, meaning that for the POLES dataset non-Annex I reduction of $20 \%$ compared to baseline and Annex I reductions of 25\% compared to 1990 levels are not sufficient to achieve a $2{ }^{\circ} \mathrm{C}$ target with a likely chance. All cases are still below $46 \mathrm{GtCO}_{2} \mathrm{eq}$, the level that would be consistent with a medium chance of reaching the $2{ }^{\circ} \mathrm{C}$ target.

As expected, global abatement costs in Fig. 3 increase with more stringent global targets. For the least stringent target, global

\footnotetext{
${ }^{11}$ Range in UNEP (2010) refers to 20th and 80th percentile values of the total range. Both the range and the median numbers presented here are rounded to the nearest decimal, giving $44 \mathrm{GtCO}_{2}$ eq. However, the upper end of the range is slightly above $44 \mathrm{GtCO}_{2}$ eq and the median slightly below. This is an indication that most of the estimates used in UNEP (2010) are close to $44 \mathrm{GtCO}_{2} \mathrm{eq}$.

12 Range in UNEP (2010) refers to 20th and 80th percentile values of the total range.
}

costs are projected to be $0.22-0.35 \%$ of GDP, while global costs are $1.7 \%$ of GDP for the most stringent target (i.e. case 9p). It should be noted that these costs exclude the costs of REDD. Taking the projections of Kindermann et al. (2008) for the costs of REDD, an ambitious reduction of deforestation emissions would lead to global costs between 17.2 and 28 USD billion/yr for the period 2005-2030. The higher end of this range would imply an increase in abatement costs of $2-20 \%$, depending on the case.

For the most stringent global target (cases 9 and 9p of Fig. 2), the case based on the TIMER MAC curves, (case 9) is infeasible, given the lack of mitigation potential below the maximum carbon price of $1000 \mathrm{US} \$ / \mathrm{tC}$. The model uses all the mitigation potential available according to the MAC curves and if more reductions are required in order to achieve the target it assumes that the additional reductions take place at the maximum price. We still present the results for case 9 in Fig. 3, but it should be noted that due to the above costs are somewhat underestimated for this case.

Fig. 3 also shows that for all mitigation cases, the calculations based on POLES data lead to somewhat higher global emissions and higher abatement costs. The higher emissions result from a higher non-Annex I emission baseline according to POLES. This explains why global emissions are above $44 \mathrm{GtCO}_{2} \mathrm{eq}$ in case $2 \mathrm{p}$, but below this level in case 2 , as previously mentioned. The higher cost estimates are a result of technology description. In general, the TIMER MAC curves lead to lower abatement costs, in particular in Annex I countries: in TIMER there is more convergence in MAC curves across regions. A comparison of MAC curves of TIMER and POLES (and other models) for the Annex I regions is provided by Amann et al. (2009).

\subsection{Distribution of Annex I and non-Annex I costs}

Fig. 4 shows the trade-offs between Annex I and non-Annex I abatement costs for the different cases, based on the conceptual framework of Fig. 1.

Fig. 4 shows that abatement costs for Annex I are higher for the POLES than for the TIMER MAC curves, whereas the opposite is true for non-Annex I. This also has an effect on the use of CDM, which is much higher for the POLES MAC curves than for TIMER. This is a result of the more pronounced differences in the marginal abatement costs between the Annex I and non-Annex I countries according to POLES MAC curves, together with a higher POLES baseline for non-Annex I countries. Increasing the nonAnnex I reduction target leads to less CDM (as more needs to be used domestically to meet the target), and also increases Annex I abatement costs (as a lower share of the Annex I target can be met via $\mathrm{CDM}$ ). In most of the cases, the Annex I countries as a group are net buyers in the market and non-Annex I are net sellers. However, for the most stringent target for non-Annex I in combination with less ambitious Annex I targets (cases 3, 6 and $3 p$ ) the situation is the opposite: Annex I becomes a seller of carbon credits.

Annex I costs range from $0.2 \%$ to $2.3 \%$ of GDP in 2020 for all TIMER and POLES MAC curves cases. Non-Annex I costs range from $-0.4 \%$ to $1.2 \%$ of GDP (the gains result from the financial revenues from emission trading and $\mathrm{CDM}$ ). According to the criteria of Section 2, non-Annex I costs should be lower than Annex I costs to be politically acceptable. The cases 2, 3, 6 and 3p and $6 \mathrm{p}$ do not meet this condition. Cases 7 and $4 \mathrm{p}, 7 \mathrm{p}$ and $8 \mathrm{p}$ do not meet the condition of positive non-Annex I costs.

\subsection{Environmental, political and economic considerations combined}

All cases with a green square in Fig. 4 have likely chance (probability above 66\%) to achieve a $2{ }^{\circ} \mathrm{C}$ target as discussed in 

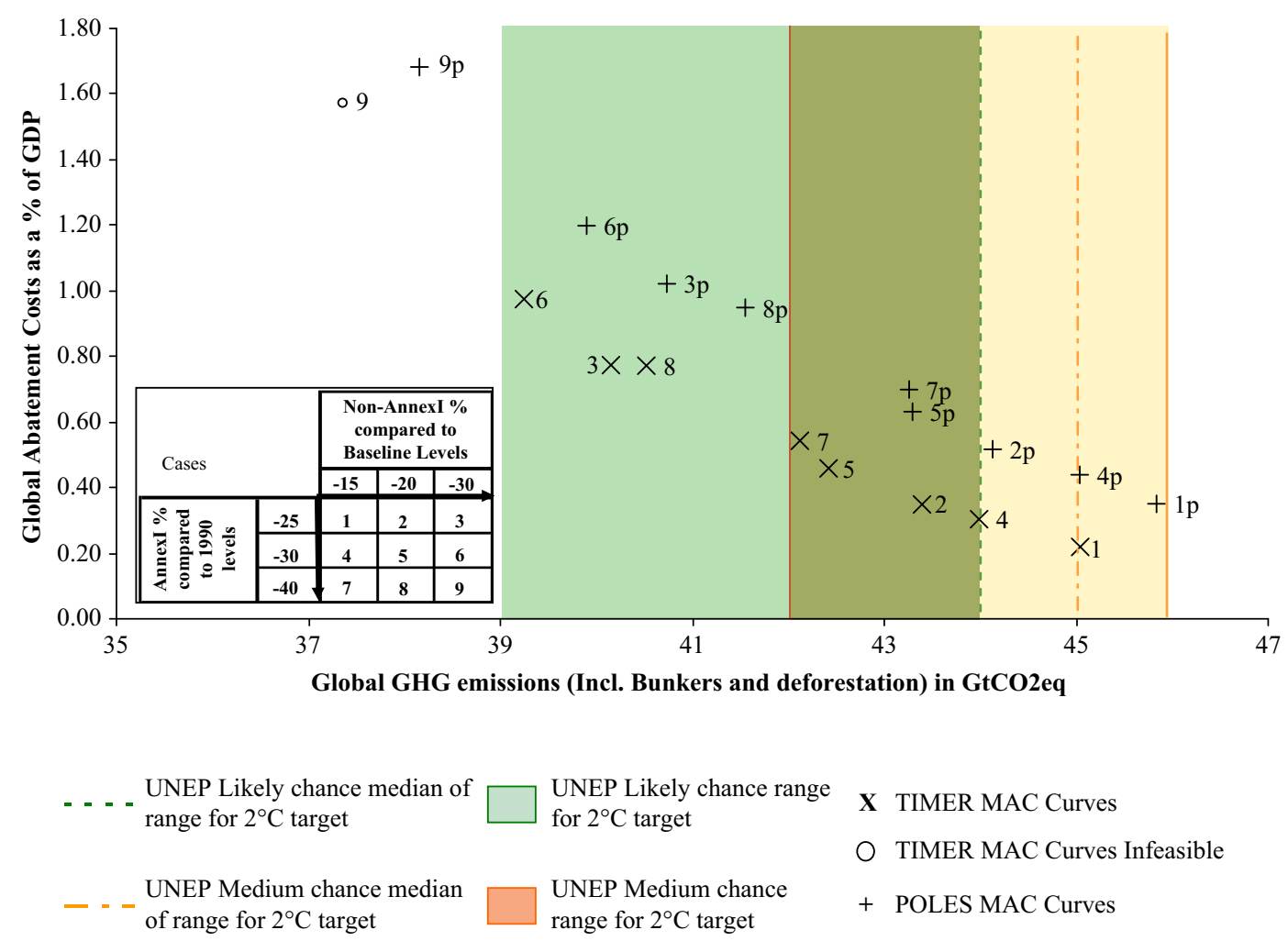

Fig. 3. Global GHG emissions versus global abatement costs as share of GDP in 2020 for the analysed cases.

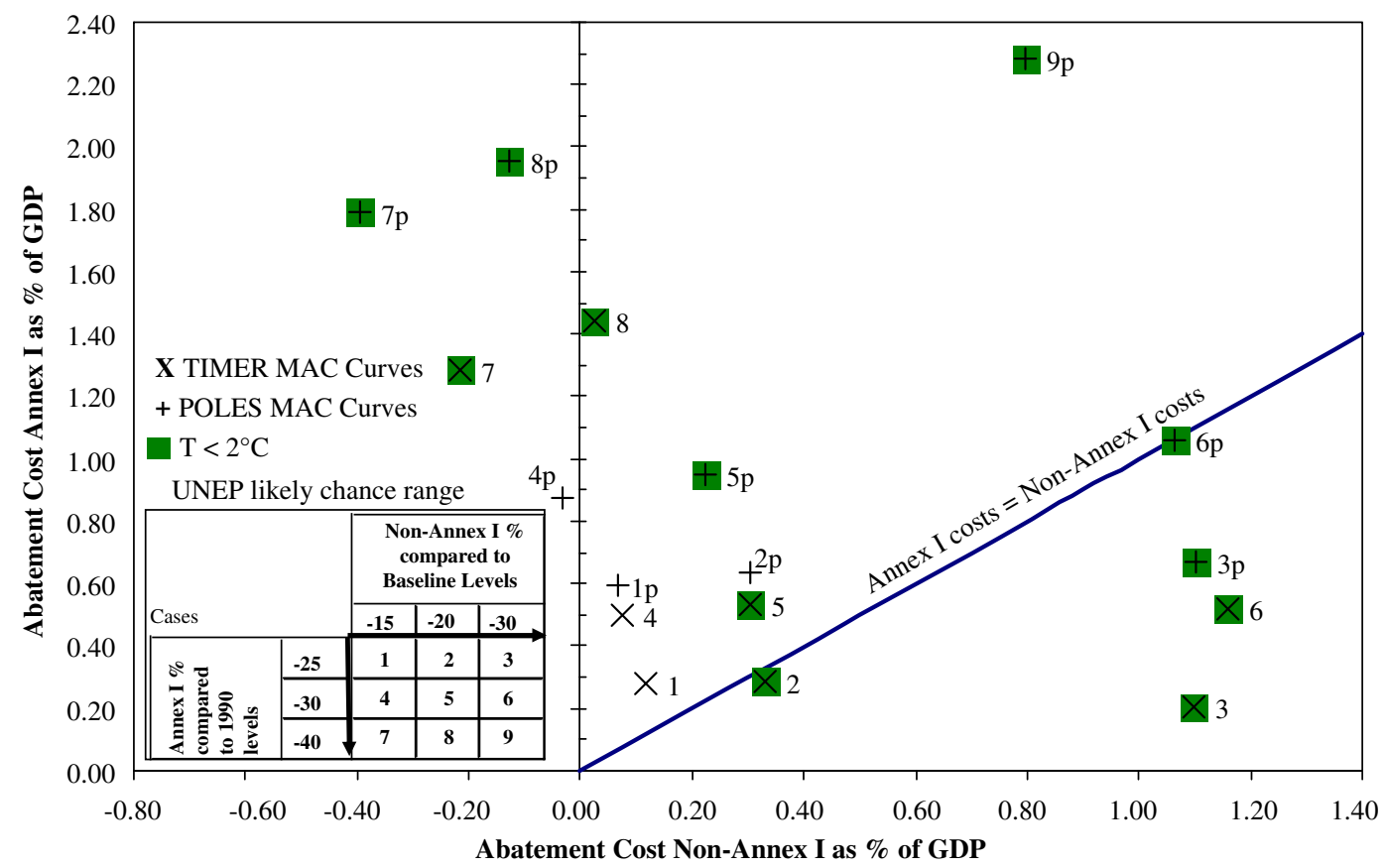

Fig. 4. Non-Annex I versus Annex I abatement costs as share of GDP (measured in Purchasing Power Parity, PPP) in 2020 for the analysed cases.

Section 4.1. Fig. 4 superposes the environmental and political criteria. Cases 5, 8, 5p and 9p are the only cases fulfilling both the environmental and political criteria as proposed in the conceptual framework. They correspond to the cases from the medium to the high end of the 2020 reduction ranges for Annex I and non-Annex I. Those cases in the low end of the reduction ranges for Annex I and non-Annex I (e.g., 1, 4, 1p, 4p and 2p) fulfil a less strict environmental criterion (i.e. a medium chance for meeting $2{ }^{\circ} \mathrm{C}$ ).

From the four remaining cases (i.e. 5, 5p, 8 and 9) only the combination with a 30\% Annex I reduction below 1990 levels and $20 \%$ non-Annex I reduction below baseline levels fulfil all criteria for both TIMER and POLES datasets (i.e. 5 and 5p). Cases 8 and 9p 
are only possible for one model dataset. More precisely, case 8 fulfils all criteria for TIMER MAC curves only and results in gains for non-Annex I for POLES MAC curves, while case 9 is not achievable when using TIMER MAC curves. The reductions of case 8 are 15\% higher than those of case 5 and global abatement costs are also higher. Case 9p is the most ambitious case that fulfils the criteria, although just for one model dataset, leading to a global emission level of $38 \mathrm{GtCO}_{2} \mathrm{eq}$ and with abatement costs 3.6 times of those in case 5 .

\section{Sensitivity of results to emissions trading level}

Up to now, we assumed the same emissions trading conditions for all cases, i.e. full emissions trading within the Annex I region and the use of CDM with different accessibility estimates for nonAnnex I (see Table 1). In this section we analyse the impact of these assumptions on the results. For this, we show the implication of both (1) more restricted trade assumptions and (2) full emissions trading (thus less restricted) for both the TIMER and POLES MAC curves. For TIMER, we focus on case 8 (40\% Annex I reduction and $20 \%$ non-Annex I reduction) and for POLES on case 5p (30\% Annex I reduction and 20\% non-Annex I reduction). The availability of CDM in the more restricted emissions trading case is, for each group of regions, half of that in the default cases as described in Section 3.4. For the full emissions trading case (no trade restriction) the CDM availability is $100 \%$ for all regions.

Fig. 5 shows the abatement costs for Annex I relative to those of non-Annex I as share of GDP for the default cases 8 and 5p, for the more restricted emissions trade and the full emissions trade versions of these cases.

As expected, in the more restricted trading cases global costs become higher, mainly due to higher costs of Annex I. This is especially the case for the TIMER MAC curves. Global abatement costs increase from $0.8 \%$ of global GDP in the default case to $0.9 \%$ in the restricted emissions trading for case 8 . For case $5 p$ the increase is from $0.65 \%$ to $0.7 \%$. These results are caused by the increase in domestic action of Annex I regions (with high marginal costs) when trading is restricted. The domestic action of Annex I as a group increases from $80 \%$ to $90 \%$ of the total reduction target for both cases 8 and 5p (the remainder being achieved by $\mathrm{CDM}$ ). The non-Annex I domestic action reduces proportionally from around $120 \%$ to $110 \%$ of the total reduction target-CDM again explaining why domestic emission reductions are higher than the target.

The full emissions trading cases lead to opposite results. More emissions trading between the regions decreases global abatement costs, since reductions are taken wherever it is cheapest to do so. For the POLES MAC curves case, about 50\% more carbon credits are traded and in the TIMER MAC curves case, the increase is around $60 \%$, both compared to the default cases.

In other words, the sensitivity of the trade assumptions on regional abatement costs is considerable: it changes the global costs and also the level of emission trading by CDM. Interestingly enough, in both cases the different trade assumptions did not move cases 8 and $5 p$ out of the 'green area' of the conceptual framework in Fig. 1. In other words, Annex I costs remained above those of non-Annex I and the global reductions remained sufficient for meeting the $2{ }^{\circ} \mathrm{C}$ target in both cases. For the full emissions trading cases, the non-Annex I costs increase and the Annex I costs decrease, diminishing the difference between Annex I and non-Annex I abatement costs. The increase in non-Annex I costs can be explained by the higher supply of carbon credits, which leads to a lower global carbon price and hence smaller benefits from selling emission credits. For the restricted emissions trading cases, both Annex I and non-Annex I abatement costs increase compared to the default cases.

\section{Analysis of results in the current policy context}

The recent submissions of country pledges and action plans to the UNFCCC as part of the Copenhagen Accord are likely to fall short in achieving stabilising atmospheric concentrations of GHG at $450 \mathrm{ppm} \mathrm{CO}_{2}$ eq in the long term. Even in the most optimistic scenario - in which the high ambitious, conditional pledges and mitigation actions of all countries are implemented and strict accounting rules for land use and the use of emission surpluses

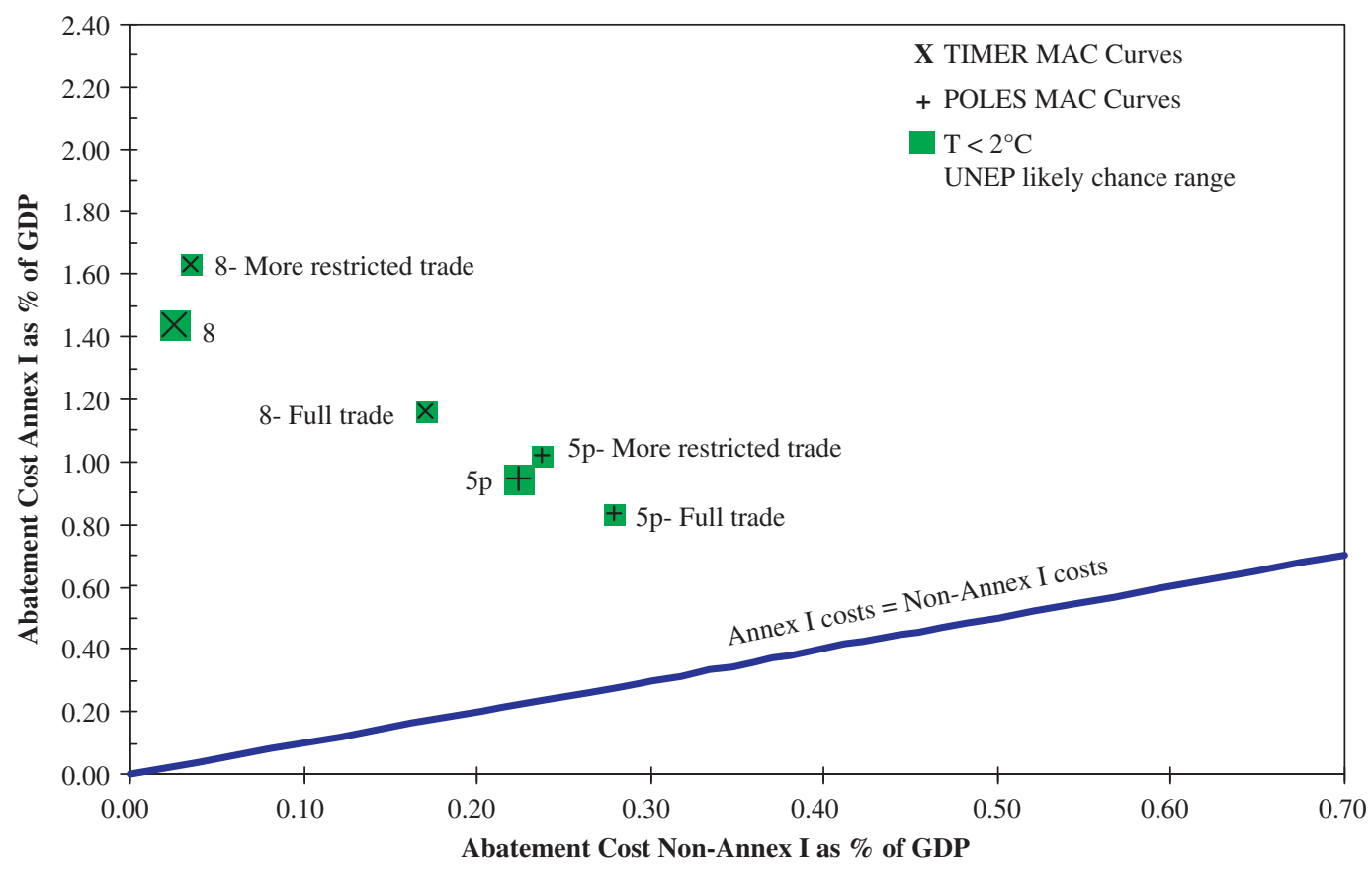

Fig. 5. Implications of different emissions trading assumptions on Annex I and non-Annex I abatement costs. 
are assumed - the emission reductions in 2020 are not consistent with most scenarios in the literature that lead to $450 \mathrm{ppm} \mathrm{CO}_{2}$-eq (e.g., den Elzen et al., 2011b; Rogelj et al., 2010; UNEP, 2010).

This can also be shown in reference to the framework and calculations introduced in this paper. When comparing the global emission levels of the most optimistic interpretation of the pledges and actions from UNEP (2010) with those of the case with reductions of 30\% below 1990 levels for Annex I and 20\% below baseline levels for non-Annex I (cases 5 and $5 p$ that meet all criteria for both model costs estimates, i.e. TIMER and POLES MAC curves), an additional effort of about 6 to $7 \mathrm{GtCO}_{2} \mathrm{eq}$ would be required to meet the global emission levels of cases 5 and $5 \mathrm{p}$, which are around $42-43 \mathrm{GtCO}_{2} \mathrm{eq}$, including bunkers and land use emissions, respectively. Focusing on the less optimistic interpretation of the Copenhagen accord pledges would show an even greater difference, $10-11 \mathrm{GtCO}_{2} \mathrm{eq}$.

den Elzen et al. (2011b) indicate that Annex I pledges lead to a reduction below 1990 levels between 12\% and 18\% depending mainly on the conditionality of the pledges. For non-Annex I a reduction between $8 \%$ and $10 \%$ below baseline levels is indicated as the resulting reduction from the submissions to the Copenhagen accord. Cases 5 and $5 p$ (that fulfil the environmental, political and economic criteria of our framework) assume reductions of 30\% below 1990 levels for Annex I and 20\% below baseline levels for non-Annex I.

In international negotiations for the agreement of emission reduction targets for different regions and countries, a large set of issues has to be dealt with simultaneously. In this paper, we have derived a negotiation space based on a set of criteria that can be directly derived from the ongoing negotiations. Clearly, the Copenhagen Accord pledges do not fall within the space drawn up by the criteria.

One of the caveats is that to some degree we have made some interpretations in setting up our criteria (e.g., a lower probability of achieving the $2{ }^{\circ} \mathrm{C}$ target may be chosen, or a deliberate "delayed-response" pathway in terms of emissions). Still, an important message is that negotiations should focus on raising the ambition of the current pledges towards a point within the space drawn up in this paper. A similar point was drawn by Peterson et al. (2011), where calculations with a Computable General Equilibrium (CGE) model showed that the announced Copenhagen pledges are not ambitious in terms of $\mathrm{CO}_{2}$ emission reductions.

\section{Conclusion}

In this paper we describe the bargaining space for the international climate negotiations as a multi-criteria field that involves considerations in the economic, political and environmental areas. In the paper, we considered a set of possible criteria that would define this space. We assume that from an environmental viewpoint, global emissions by 2020 should reach a level consistent with a likely chance to meet a $2{ }^{\circ} \mathrm{C}$ climate target. Secondly, we assume that parties would try to minimise global abatement costs (as this could in principle also ensure low regional costs). Third, we assume that parties would accept the concept of "common but differentiated responsibilities and respective capabilities" (UNFCCC, 1992). In that context, we introduced the notion that the costs of non-Annex I should not be higher than those of Annex I regions, as a share of GDP. At the same time, we also assumed that it would not be acceptable if non-Annex I, as a group, would have negative abatement costs.

Obviously, these criteria are to some degree subjective, but each of them has quite some support within the current negotiations. Our aim is not to propose these criteria themselves but indicate how acceptance of these criteria (or similar ones) would impact the bargaining space for the international negotiations. It should also be noted that translating these criteria into quantified numbers depends on the model used: for that reason we have in fact used two independent models datasets: IMAGE/TIMER and POLES. In the calculations, we have specifically looked at the outcomes of relevant combinations for the reduction targets in Annex I and non-Annex I countries in 2020 versus the criteria. The ranges explored for these country groups are those described in the IPCC AR4 for Annex I (i.e. 25-40\% below 1990 levels) and by den Elzen and Höhne (2008) for non-Annex I (i.e. 15-30\% below baseline levels).

Broadening the discussion from mainly environmental rationales of setting targets to economic and political rationales substantially reduces the likely reduction ranges for Annex I and non-Annex I. In fact, only one case satisfies our environmental, economic and political criterion for both energy models. This is the case with a $30 \%$ reduction target for Annex I compared to 1990 levels combined with a 20\% reduction target for nonAnnex I compared to baseline levels (i.e. around $20-30 \%$ above 2005 levels according IMAGE/TIMER and POLES baselines, respectively). The abatement costs for these cases ranges between $0.45 \%$ and $0.65 \%$ of GDP for the world, between $0.53 \%$ and $0.95 \%$ of GDP for Annex I and between $0.22 \%$ and $0.30 \%$ of GDP for non-Annex I in 2020. For Annex I the range in terms of emission levels goes from 12 to $13 \mathrm{GtCO}_{2} \mathrm{eq}$, for non-Annex I from 26 to $27 \mathrm{GtCO}_{2} \mathrm{eq}$ and for the world around $39 \mathrm{GtCO}_{2} \mathrm{eq}$, excluding bunkers and land use emissions.

Several trade-offs arise from broadening the perspective for achieving a successful negotiations outcome. For instance not all cases acceptable under the environmental criterion did meet the other criteria. This shows the importance of assessing reduction targets according to different viewpoints as part of a broader framework. Realizing the existence of the space could facilitate the decision-making process by narrowing the options to those with an acceptable outcome. Above all, the framework is useful as a conceptual framework to look at the negotiations, instead of earlier frameworks that seem to formulate these targets as a much simpler trade-off between Annex I and non-Annex I emissions.

Obviously, there are still many other factors influencing the climate policy debate as well as it is important to interpret the results taking into account the caveats used in the analysis. For instance, the allocation of reductions among individual countries in order to achieve the aggregate Annex I and non-Annex I targets may play a crucial role, as well as the distribution of costs for REDD. This could especially be important if the level of emissions trading is restricted, as our sensitivity analysis shows. Finally, it should be stated that lower reduction targets of Annex I could also be politically feasible according to our criterion, under the condition that Annex I countries (partly) finance abatement costs of non-Annex I countries-next to using CDM and emissions trading.

\section{Appendix A. Description of the energy models TIMER and POLES}

TIMER - The global energy model of IMAGE (TIMER) looks into long-term trends in the energy system (van Vuuren et al., 2004, 2007). The model describes the demand and supply of 9 final energy carriers and 10 primary energy carriers for 26 world regions. The model focuses on several dynamic relationships within the energy system, such as inertia, learning-by-doing, depletion and trade among the different regions. The demand sub-model of TIMER determines demand for fuels and electricity 
in five sectors (industry, transport, residential, services and other) based on structural change, autonomous and price-induced change in energy intensity ('energy conservation') and pricebased fuel substitution. The demand for electricity is fulfilled by fossil-fuel or bio-energy based thermal power, hydropower, nuclear power and solar or wind. All technologies are chosen on the basis of relative costs (using multinomial logit equations). The exploration and exploitation of fossil fuels (either for electricity or direct fuel use) is described in terms of depletion and technological development. Bio-energy can be used in place of fossil fuels. Emissions are calculated by multiplying the data on energy consumption and production with fuel- and region specific emission factors that are derived from the EDGAR database. For most gases, the emission factors are assumed to decline over time as a result of technology development and as to reflect the notion of increasing environmental awareness with rising income levels. For $\mathrm{CO}_{2}$, emission factors stay constant over time-unless the model explicitly selects technology with carbon-capture-andstorage (on the basis of costs).

POLES -POLES is a global simulation model of the energy system (Criqui et al., 1999; Russ and Criqui, 2007; Russ and Van Ierland, 2009). The dynamics of the model is based on a recursive simulation process of energy demand and supply with lagged adjustments to prices and a feedback loop through the international energy price. The model is developed in the framework of a hierarchical structure of interconnected modules at the international, regional, and national levels. It contains technologicallydetailed modules for energy-intensive sectors, including power generation, iron and steel, the chemical sector, aluminium production, cement making, non-ferrous minerals and modal transport sectors (including aviation and maritime transport). All energy prices are determined endogenously. Oil prices in the long-term depend primarily on the relative scarcity of oil reserves. The world is broken down into 47 regions, for which the model delivers detailed energy balances. The model is continuously being enhanced in both detail and in the degree of regional disaggregation.

\section{References}

Anger, N., Sathaye, J.A., 2008. Reducing Deforestation and Trading Emissions: Economic Implications for the post-Kyoto Carbon Market. Discussion Paper No. 08-016, 〈ftp://ftp.zew.de/pub/zew-docs/dp/dp08016.pdf $\rangle$, Centre for European Economic Research (ZEW), Mannheim, Germany.

Amann, M., Rafaj, P., Höhne, N., 2009. GHG Mitigation Potentials in Annex I Countries. Comparison of Model Estimates for 2020. IR-09-034, September, IIASA, Laxenburg, Austria.

Bouwman, A.F., Kram, T., Klein Goldewijk, K., 2006. Integrated Modelling of Global Environmental Change. An Overview of IMAGE 2.4. Netherlands Environmental Assessment Agency, available at: 〈www.mnp.nl $\backslash e n\rangle$, Bilthoven, The Netherlands.

Bosetti, V., Lubowski, R., Golub, A., Markandya, A., 2011. Linking reduced deforestation and a global carbon market: implications for clean energy technology and policy flexibility. Environment and Development Economics, $1-27$.

Busch, J., Strassburg, B., Cattaneo, A., et al., 2009. Comparing climate and cost impacts of reference levels for reducing emissions from deforestation. Environmental Research Letters, 11.

Clarke, L., Edmonds, J., Krey, V., Richels, R., Rose, S., Tavoni, M., 2009. International climate policy architectures: overview of the EMF 22 International Scenarios. Energy Economics 31 (2), S64-S81.

Criqui, P., 2002. GECS Final Report Section 6: Detail report. GECS—Research Project No EVK2-CT-1999-00010, Thematic Programme: Environment and Sustainable Development, DG Research Fifth Framework Programme, CNRS-IEPE, Grenoble.

Criqui, P., Mima, S., Viguier, L., 1999. Marginal abatement costs of $\mathrm{CO}_{2}$ emission reductions, geographical flexibility and concrete ceilings: an assessment using the POLES model. Energy Policy 27 (10), 585-601.

Dellink, R., Briner, G., Clapp, C., 2010. Costs, Revenues, and Effectiveness of the Copenhagen Accord Emission Pledges for 2020, OECD Environment Working Papers, No. 22. OECD Publishing.

den Elzen, M.G.J., Hof, A.F., Beltran, A.M., Grassi, G., Roelfsema, M., van Ruijven, B.J., van Vliet, J., van Vuuren, D.P., 2011a. The copenhagen accord: abatement costs and carbon prices resulting from the submissions. Environmental Science \& Policy 14, 28-39.

den Elzen, M.G.J., Hof, A.F., Roelfsema, M., 2011b. The emissions gap between the Copenhagen pledges and the $2{ }^{\circ} \mathrm{C}$ climate goal: options for closing and risks that could widen the gap. Global Environmental Change 21 (2), 733-743.

den Elzen, M.G.J., Höhne, N., 2008. Reductions of greenhouse gas emissions in Annex I and non-Annex I countries for meeting concentration stabilisation targets. Climatic Change 91 (3-4), 249-274.

Eliasch, J., 2008. Eliasch Review: Climate Change: Financing Global Forests Office of Climate Change (OCC), London, UK, available at: 〈www.occ.gov.uk〉.

Enerdata, 2010. POLES Model Marginal Abatement Cost Curves (MACCs) based on the World Energy Outlook 2009, Enerdata, Grenoble, France, see: 〈http://www. enerdata.net/enerdatauk/subscriptions/marginal-abatement-cost-curves-MACCs. php >

Edenhofer, O., Knopf, B., Barker, T., Baumstark, L., Bellevrat, E., et al., 2010. The economics of low stabilization: model comparison of mitigation strategies and costs. The Energy Journal 31, 11-48.

European Council, 2011. Council conclusions: Follow-up to the Cancún Conference 3075th ENVIRONMENT Council meeting Brussels, 14 March.

Fankhauser, S., Martin, N., 2010. The economics of the CDM levy: revenue potential, tax incidence and distortionary effects. Energy Policy 38 357-363.

Gupta, S., Tirpak, D.A., Burger, N., et al., 2007. Policies, instruments and co-operative arrangements. In: Metz, B., Davidson, O.R., Bosch, P.R., Dave, R., Meyer, L.A. (Eds.), Climate Change 2007: Mitigation. Contribution of Working Group III to the Fourth Assessment Report of the Intergovernmental Panel on Climate ChangeCambridge University Press, Cambridge, UK.

IEA, International Energy Agency, 2007. World Energy Outlook 2007. Paris, France IEA, International Energy Agency, 2009. World Energy Outlook 2009. Paris, France. IMF, International Monetary Fund, 2009. World Economic Outlook. Contractionary Forces Receding But Weak Recovery Ahead. Update July 8, Washington, DC.

Jotzo, F., Michaelowa, A., 2002. Estimating the CDM market under the Marrakech Accords. Climate Policy 2, 179-196.

Karousakis, K., Corfee-Morlot, J., 2007. Financing mechanisms to reduce emissions from deforestation: issues in design and implementation. COM/ENV/EPOC/ IEA/SLT(2007)7. Organisation for Economic Co-operation and Development/ International Energy Agency, Paris, France.

Klepper, G., Peterson, S., 2006. Marginal abatement cost curves in general equilibrium: the influence of world energy prices. Resource and Energy Economics 28 (1) 1-23.

Knopf, B., Edenhofer, O., Flachsland, C., Kok, M.T.J., Lotze-Campen, H., Luderer, G., Popp, A., van Vuuren, D., 2010. Managing the low-carbon transition-from model results to policies. The Energy Journal Special Issue, The Economics of Low Stabilization 31, 223-245.

Kindermann, G., Obersteiner, M., Sohngen, B., et al., 2008. Global cost estimates of reducing carbon emissions through avoided deforestation. Proceedings of the National Academy of Sciences of the United States of America 105 (30) 10302-10307.

Lucas, P., van Vuuren, D.P., Olivier, J.A., den Elzen, M.G.J., 2007. Long-term reduction potential of non- $\mathrm{CO}_{2}$ greenhouse gases. Environmental Science \& Policy 10 (2), 85-103.

Meinshausen, M., Hare, W.L., Wigley, T.M.L., van Vuuren, D.P., den Elzen, M.G.J. Swart, R., 2006. Multi-gas emission pathways to meet climate targets. Climatic Change 75 (1-2), 151-194.

Metz, B., Berk, M., den Elzen, M.G.J., De Vries, B., Van Vuuren, D.P., 2002. Towards an equitable global climate change regime: compatibility with Article 2 of the Climate Change Convention and the link with sustainable development. Climate Policy 2, 211-230.

Metz, B., Davidson, O.R., Bosch, P.R., Dave, R., Meyer, L.A., 2007. Climate Change 2007: Mitigation. Contribution of Working Group III to the Fourth Assessment Report of the Intergovernmental Panel on Climate Change. Cambridge University Press, Cambridge, UK.

Michaelowa, A., Jotzo, F., 2005. Transaction costs, institutional rigidities and the size of the clean development mechanism. Energy Policy 33 (4), $511-523$.

O’Neill, B.C., Riahi, K., Keppo, I., 2009. Mitigation implications of midcentury targets that preserve long-term climate policy options. PNAS 107 (3) 1011-1016.

Peterson, E.B., Schleich, J., Duscha, V., 2011. Environmental and economic effects of the Copenhagen pledges and more ambitious emission reduction targets. Energy Policy (39)).

Rogelj, J., Meinshausen, M., Nabel, J., Chen, C., Hare, W., Markmann, K., Schaeffer, M., Macey, K., Höhne, N., 2010. Copenhagen Accord pledges are paltry. Nature Report 464, 1126-1128.

Russ, P., Criqui, P., 2007. Post-Kyoto $\mathrm{CO}_{2}$ emission reduction: the soft landing scenario analysed with POLES and other world models. Energy Policy, 35786-35796.

Russ, P., Van Ierland, T., 2009. Insights on different participation schemes to meet climate goals. Energy Economics 31 (Suppl. 2), S163-S173.

UNEP, United Nations Environment Programme, 2010. The Emissions Gap Report: Are the Copenhagen Accord Pledges Sufficient to Limit Global Warming to $2^{\circ} \mathrm{C}$ or $1.5^{\circ} \mathrm{C}$ ? 〈http://www.unep.org/publications/ebooks/emissionsgapreport/ >

UNFCCC, 2011. Decision 1/CP.16. The Cancun Agreements: Outcome of the work of the Ad Hoc Working Group on Long-term Cooperative Action under the Convention. Available at: 〈http://unfccc.int/resource/docs/2010/cop16/eng/ 07a01.pdf\#page $=2>$. 
UNFCCC, United Nations Framework Convention on Climate Change, 1992. United Nations General Assembly. Nations, New York, N.Y., USA. 〈http://www.unfccc. int/resourcesUnited $>$.

van Vuuren, D.P., Riahi, K., 2011. The relationship between short-term emissions and long-term concentration targets-a letter. Climatic Change 104, 793-801.

van Vuuren, D.P., Stehfest, E., den Elzen, M.G.J., Kram, T., van Vliet, J., Deetman, S. Isaac, M., Klein Goldewijk, K., Hof, A., Mendoza Beltran, A., Oostenrijk, R., van Ruijven, B. RCP2.6: a pathway to explore the possibility to keep global mean temperature increase below $2^{\circ} \mathrm{C}$. Climatic Change, in press. van Vuuren, D.P., Hoogwijk, M., Barker, T., et al., 2009. Comparison of top-down and bottom-up estimates of sectoral and regional greenhouse gas emission reduction potentials. Energy Policy 37 (12), 5125-5139.

van Vuuren, D.P., den Elzen, M.G.J., Eickhout, B., Lucas, P.L., Strengers, B.J., Ruijven, B., Wonink, S., van Houdt, R., 2007. Stabilizing greenhouse gas concentrations at low levels: an assessment of reduction strategies and costs. Climatic Change 81 (2), 119-159.

van Vuuren, D.P., de Vries, H.J.M., Eickhout, B., Kram, T., 2004. Responses to Technology and Taxes in a Simulated World. Energy Economics 26, 579-601. 